\title{
Sex-specific pattern of spatial genetic structure in dioecious and clonal tree species, Populus alba $\mathrm{L}$.
}

\author{
Monika Dering ${ }^{1} \cdot$ Grzegorz Rączka $^{2} \cdot$ Janusz Szmyt $^{3}$
}

Received: 26 April 2016/Revised: 31 May 2016 / Accepted: 10 June 2016 / Published online: 21 June 2016

(C) The Author(s) 2016. This article is published with open access at Springerlink.com

\begin{abstract}
Fine-scale spatial genetic structure (SGS) has profound ecological and genetic consequences for plant populations, and some studies indicate that clonal reproduction may significantly enhance SGS. Clonality is widespread among dioecious species, but little is known about the relationship between clonal reproduction and SGS in the frame of sexual dimorphism. We asked the following questions: (1) Is there a sexually dependent pattern of SGS in white poplar population? (2) What is the relationship between clonal reproduction and SGS? and (3) Does this relationship have a sex-specific component? Using 16 microsatellite markers, genetic structure including fine-scale SGS and clonality of females and males of white poplar were investigated. Significant SGS was noted for both sexes at the ramet and genet levels. At the genet level, males had 2.7-fold higher SGS than that of
\end{abstract}

Communicated by P. Ingvarsson

Electronic supplementary material The online version of this article (doi:10.1007/s11295-016-1028-5) contains supplementary material, which is available to authorized users.

Monika Dering

mdering@man.poznan.pl

Grzegorz Rączka

g.raczka@wp.pl

Janusz Szmyt

jszmyt@up.poznan.pl

1 Laboratory of Systematics and Geography, Institute of Dendrology, Polish Academy of Sciences, Parkowa 5, 62-035 Kórnik, Poland

2 Department of Forest Management, University of Life Sciences, Wojska Polskiego 71C, 60-625 Poznań, Poland

3 Department of Forest Silviculture, University of Life Sciences, Wojska Polskiego 69, 60-625 Poznań, Poland females. Clonality significantly contributed to SGS only in females. A sibship structure revealed with pedigree analysis and clustering-based methods among males was likely the major factor of the observed SGS. The sexes differed in their clonal growth strategies. Spatial positioning of ramets in female clones suggested foraging behavior and/or avoidance of competition, while for male clones it indicated more expansion and space colonization. The obtained results led us to conclude that sexual dimorphism in life history traits may affect the course and rate of demo-genetic processes acting in natural populations of dioecious species. To our knowledge, this is the first study demonstrating a sex-specific pattern of SGS in natural populations of dioecious species.

Keywords Spatial genetic structure $\cdot$ Clonality $\cdot$ Sexual dimorphism $\cdot$ Dioecy $\cdot$ White poplar

\section{Introduction}

The majority of plants display hermaphroditic sex expression while separation of male and female functions on different individuals, dioecy, is a low frequency sexual system in plants (ca. $6 \%$ of land plants) (Renner and Ricklefs 1995). Dioecy provides an excellent opportunity to investigate functional differentiation among sexes, i.e., sex dimorphism (Delph 1999; Dorken and Barrett 2004; Montesinos et al. 2012). This is based on the fact that sexes differ with respect to their roles and constrains, and the physical release of sexes from unity has made them possible to be under divergent evolutionary trajectories. The dissimilarity between sexes in any aspect of morphology or physiology is generally considered in the frame of the theory of resource allocation and existing conflicts between realization of different functions - survival, growth, and reproduction - in situations of limited resources 
(Bell 1980; Delph 1999). It is widely assumed that females incur higher costs of reproduction owing to flowering and fruiting processes (Lloyd and Webb 1977; Obeso 2002; Vessella et al. 2015). Consequently, this may lead to resource allocation trade-offs affecting female survival rates (Obeso 2002), growth (Iszkuło and Boratyński 2011; Iszkuło et al. 2011), clonal growth (Allen and Antos 1993) or other fitness-related traits, which in turn may give rise to sexrelated demographic patterns.

Dioecy, beyond the self-incompatibility system and inbreeding depression, is considered as one of the basic evolutionary mechanisms that ensure high cross-fertilization in trees which accounts for their high genetic diversity (Petit and Hampe 2006). Nevertheless, Nazareno et al. (2013) stated that dioecy may significantly contribute to spatial genetic structure (SGS) in natural populations of dioecious plants. Dioecious plant species analyzed by the authors had on average 6-fold higher SGS than monoecious species. According to theoretical considerations and empirical studies, seed dispersal range has a predominant impact on building SGS in natural populations (Vekemans and Hardy 2004; Heuertz et al. 2003; Chybicki and Burczyk 2013). In dioecious species, the number of seed sources is half in compared to monoecious species. The reduced number of seed-producing individuals may increase SGS since it leads to less overlap of the seed shadows of maternal individuals (Heilbuth et al. 2001). Given the fact that seeds are dispersed only by females in dioecious populations and most of the seeds are generally locally dispersed, dioecious species may experience a reduction in the seed range dispersal on a population scale (Heilbuth et al. 2001).

Clonal growth is a vegetative multiplication resulting in the emergence of a new plant genetically identical to the mother individual but potentially independent with respect to growth and reproduction. It is very widespread among plants, including tree species (Jeník 1994). Clonality has profound ecological and evolutionary consequences because the dynamic interaction between sexual and vegetative reproduction may affect population dynamics, genetic structure, and the fitness (Silvertown 2008; Vandepitte et al. 2010; Van Drunen et al. 2015). Since clonal plants may spread laterally, clonal growth in a spatially explicit framework may be perceived as a particular mode of gene dispersal which is realized throughout the emergence of every new ramet that is set somewhere in a space. Dispersal capabilities of clonally derived individuals depending on the clonal growth mode and architecture may interfere with the spatial organization of genetic information in a population affecting local SGS. Some empirical studies suggest that clonality may indeed strengthen SGS (Reusch et al. 1999; Setsuko et al. 2004; Chenault et al. 2011; Peng et al. 2015). Recent meta-analysis on SGS pattern in clonal and non-clonal tree species suggested also that clonal species may display significantly higher SGS in their populations (Dering et al. 2015).
In dioecious and clonal species, females and males may differ in clonal traits such as clonal architecture (Fujitaka and Sakai 2007), genet size (Petzold et al. 2013), ramet production (Matsushita and Tomaru 2012), clonal growth strategy (McLetchie and Puterbaugh 2000), and physiological integrity with the main ramet (Isogimi et al. 2011). Sexdependent pattern in clonal plants has been revealed also for mortality (Allen and Antos 1993) and reproductive success (Matsuo et al. 2014). No doubt all of these life-history traits may have an impact on population dynamics and demography which are closely related with fine-scale SGS. Additionally, spatial segregation of sexes (SSS) that is reported among dioecious species and leads to occupation of different microhabitats (Bierzychudek and Eckhart 1988; Sanchez-Vilas et al. 2012) may also contribute to divergent trajectories of demogenetic processes acting in patches occupied by males or females, respectively. One of the mechanisms of SSS is differential resources acquisition by sexes due to differential costs of reproduction incurred by the sexes (Bierzychudek and Eckhart 1988). Hence, spatial segregation of sexes could also be a factor of differential SGS. So far, investigations on sexdependent genetic structure in clonal plants have not been conducted. Consequently, nothing is known whether females and males of clonal species differ with respect to SGS.

In this paper, we investigated the possible existence of sexspecific SGS in dioecious and clonal tree, Populus alba L. (white poplar). SGS was quantified and compared between female and male individuals of white poplar that were sampled in a natural population. We assumed that directions and rates of demo-genetic processes may be divergent in sexes that would result in differential characteristics of SGS. Additionally, we examined if the white poplar shows significant SSS in occupation of the habitats. Finally, we compared between sexes the clonal architecture expecting dissimilarity in clonal life history traits as well.

\section{Materials and methods}

\section{Study site and sampling scheme}

Sampling was conducted in the Wielka Kępa nature reserve located near the Vistula River in Poland $\left(53^{\circ} 09^{\prime} 07.86^{\prime \prime} \mathrm{N}\right.$; $\left.18^{\circ} 11^{\prime} 51.73^{\prime \prime} \mathrm{E}\right)$. This area is a former sandy island that has merged with the riverside, and currently it is located 120 $380 \mathrm{~m}$ from the riverbank. The study site covers the area of 26.6 ha (Fig. 1). In spring of 2012, all individuals (ramets) of white poplar with a height $>150 \mathrm{~cm}$ were georeferenced using a GPS mapping system and Laser Vertex VL 400 rangefinder (Haglöf, Sweden), totally 672 ramets. The sex of at least two individuals per clone was determined during the flowering period in 2013 and confirmed in next season. Since sex is genetically determined in Populus (Paolucci et al. 2010; 
Fig. 1 Map of the study site Wielka Kępa natural reserve along Vistula river in Poland

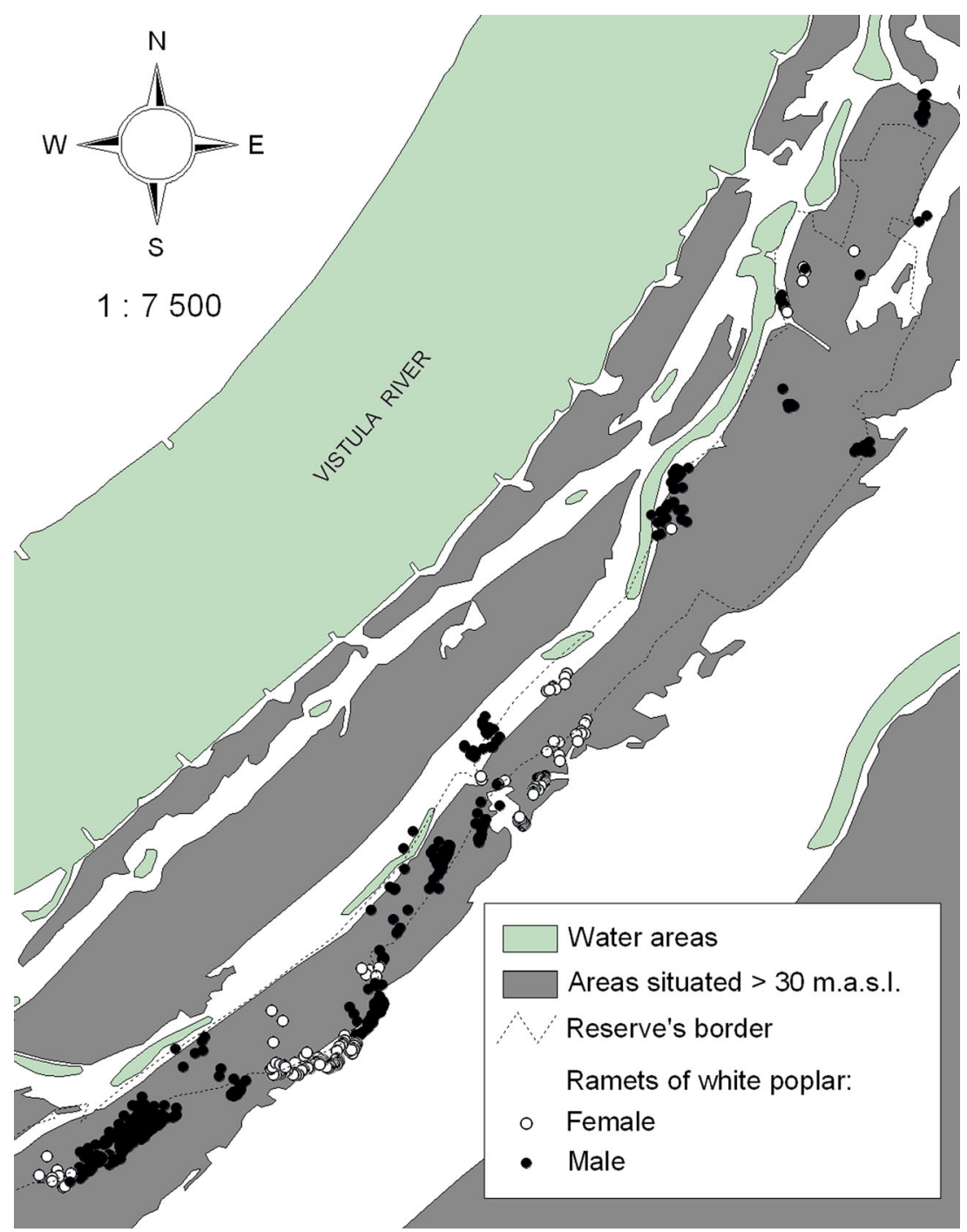

Geraldes et al. 2015), non-flowering individuals were sexed through assignment to previously sexed clones defined through genotyping.

\section{DNA extraction, genotyping, and genetic diversity}

Total DNA was extracted according to Dumolin et al. (1995) from the leaf tissues of 672 individuals. A set of 16 nuclear microsatellite markers (nSSRs) developed by van der Schoot et al. (2000) and Tuskan et al. (2004) and available at http://web.ornl.gov/sci/ipgc/ssr_resource.htm was used in the genotyping procedure as described in Dering et al. (2015) (Table 2).

INEst 1.0 (Chybicki and Burczyk 2009) was used to estimate genetic diversity parameters at the genet level in both sexes: expected $\left(H_{e}\right)$ and observed heterozygosity $\left(H_{o}\right)$, number of alleles per locus $(A)$, inbreeding coefficient of Weir and Cockerham (1984) $\left(F_{I S}\right)$, and frequency of null alleles. HardyWeinberg Equilibrium (HWE) was tested with Genepop
(Rousset 2008). The significance of difference in $H_{e}, H_{o}$, and $A$ between sexes was tested with permutation tests $(10$, 000 permutations).

\section{Clonality and clonal architecture}

Identification of genets (clones) in both sexes was based according to the method implemented in the software GeneClone 2.0 (Arnaud-Haond and Belkhir 2006), which was also used to estimate the probability of occurrence of each observed genotype (psex) more than 1 to $n$ under sexual reproduction with random mating and linkage equilibrium. The female to male sex ratio was determined at two levels: (1) the ramet sex ratio referring to all trees present in the population and (2) the genet sex ratio referring to defined genets present in the population. Deviation from a 1:1 sex ratio was tested using chi-square tests.

The clonal diversity $(R)$ of the population was estimated as $R=(G-1) /(N-1)$ where $G$ is the number of genets and $N$ is 
the number of sampled individuals (ramets) (Dorken and Eckert 2001). Clonal architecture was expressed with a clonal dominance index $(D c)$ calculated following Ohsako (2010) for each of the sexes for each clone with $\geq 3$ ramets:

$D c=\left(N_{R}-1\right) /\left(N_{T}-1\right)$ where $N_{R}$ is the number of ramets of targeted genet and $N_{T}$ is the total number of ramets (including ramets not belonging to this genet) occurring within the spatial range of the targeted genet, $G_{A}\left(\mathrm{~m}^{2}\right)$. If the spatial area of the targeted genet is occupied only with ramets belonging to this genet, then $N_{R}=N_{T}$, and the dominance index reaches its maximum value of 1 . The lower value of $D c$, the looser clonal architecture and higher intermingling of clones is observed which we referred here as phalanx-like type of clonal architecture. The area of the female and male genets, $G_{A}\left(\mathrm{~m}^{2}\right)$, was defined as the sum of the areas taken by all ramets belonging to that genet and was obtained from our previous investigations conducted in this population (Dering et al. 2015). Using ESRI ${ }^{\circledR}$ ArcGIS 9.3, we computed the intra-clonal nearest neighbor distance, $d_{\text {near }}$, which is the distance to the nearest ramet of the same clone for each sex independently. The relation between the $N_{R}$ and mean $d_{\text {near }}$ for clones with $N_{R} \geq 3$ was investigated for both sexes with regression analysis using JMP 11.0.0 (SAS Institute Inc.).

The size of genets in both sexes was described as (1) the number of ramets, $N_{R}$; (2) the maximum distance between ramets, $d_{\max }$; and (3) the area occupied by the genet, $G_{A}$. Regression analysis was used in order to determine the relationship between (1) $N_{R}$ and $G_{A}$ and (2) $N_{R}$ and $d_{\max }$ for clones of both sexes with $N_{R} \geq 3$ (JMP 11.0.0; SAS Institute Inc.). We investigated the relationships between number of ramets and spatial characteristics of clonal growth (area occupied and inter-ramet maximum distance) in order to find out which of the two processes, namely densification or expansion, characterizes the female and male clonal growth strategy.

\section{Spatial genetic structure and population substructure}

SGS was explored for sexes separately at the ramet and genet levels. The coordinates of genets were calculated as the clone origin following the method of Chong et al. (2013). Spatial autocorrelation analysis of kinship among genets and ramets was conducted with SPAGeDi v. 1.2 (Hardy and Vekemans 2002) for both sexes separately. The average multilocus kinship coefficient $\left(F_{i j}\right)$ was computed according to Loiselle et al. (1995) and averaged within each of the 11 distance classes that were set up after few testing analysis aiming fulfilling analysis requirements: $10,55,150,250,360,480,600,800,950$, 1.300 , and $2.160 \mathrm{~m}$. Average values of $F_{i j}$ were regressed on the logarithm of distance $\ln \left(d_{i j}\right)$ in order to obtain the regression slope, $b$, which quantifies the SGS. Additionally, the $S p$ statistic developed by Vekemans and Hardy (2004) was computed according to the formula $-b /\left(1-F_{(1)}\right)$, where $F_{(1)}$ refers to the mean kinship coefficient for individuals from the first distance class. To test for SGS under the null hypothesis of no correlation of $F_{i j}$ and $\ln \left(d_{i j}\right)$, the spatial positions of individuals were permuted 10,000 times and confidence intervals were obtained from jackknifing over loci. Test $Z$ was used in order to test the significance of the difference between sexes in the values of the regression slopes at the genet and at the ramet level.

In order to test the population substructure that can be the factor of SGS (Meirmans 2012), a Bayesian clustering analysis was performed with Structure v.2.3.4 (Pritchard et al. 2000) under the models of admixture and correlated allele frequencies. After testing phase, the final analysis was conducted for each of the sexes separately and included modeling the clusters from $K=1$ to $K=8$ for males and from $K=1$ to $K=6$ for females with 10 replicates of 250,000 iterations with burn-in phase of 100,000. To explore the result obtained with Structure, CLUMPAK (Cluster Markov Packager Across K; Kopelman et al. 2015) was used. CLUMPAK allowed us was for defining the best $K$ using method of Evanno et al. (2005) and creating the graphical representation of the ancestry proportions of individuals (bar plots) in each cluster.

\section{Relatedness}

Since the existence of family structure may be responsible for SGS emergence due to substructuring of population, we used Colony (Wang and Santure 2009) to infer the frequencies of possible pairs of full sibs, half sibs, and unrelated individuals in the studied population. The full-likelihood-based analysis (medium likelihood precision and medium length of run) was done under the assumption of polygamy and no inbreeding, as suggested for dioecious species in manual. Locus-specific estimates of null allele frequencies were used as the surrogates for allelic dropout rates, together with genotyping errors provided by INEst 1.0. software (Chybicki and Burczyk 2009). Only relationships supported with a probability of $>0.9$ were scored.

\section{Spatial dependence in the occurrence of sexes}

To analyze the spatial pattern of ramets, we used the methods from the second order functional statistics. As a summary statistics, we used the pair correlation function, $g(r)$, being the normalized neighborhood density function. It can be defined as the expected density of points (ramets) of the average point of the pattern at a certain distance $r$, divided by the mean density $(\lambda)$ of points (Illian et al. 2008; Wiegand et al. 2009; Wiegand and Moloney 2014). We used the double-cluster process as the null model. The double-cluster process has five parameters: $r$ - the distance; $\sigma_{1}, \sigma_{2}$-the size of small and large clusters, respectively; $\rho_{1}, \rho_{2}$-the intensities of small and large clusters, respectively (Wiegand and Moloney 2014). While univariate analysis aims to describe the spatial 
arrangement of a given type of points (individuals), bivariate analysis is concerned with description of the spatial correlation structure of the bivariate point patterns, e.g., males and females in our study. To find out whether the process that distributed sex attributes among the individuals acted in a spatially uncorrelated way, we used the random labeling as the null model. In this model, the qualitative marks (sex) are randomly shuffled over the individuals of the unmarked pattern (Illian et al. 2008; Jacquemyn et al. 2010; Wang et al. 2010; Wiegand and Moloney 2014). We contrasted the observed summary statistics to that expected under the specific null models chosen. Approximate $95 \%$ simulation envelopes were calculated for each distance $r$, using the fifth lowest and the fifth highest values of 199 Monte Carlo simulations of the null model.

Considering sex-related cost of reproduction found in dioecious species, we choose water availability factor as potentially involved in SSS. Due to lack of direct data on habitat heterogeneity with respect to water availability, we tested indirectly this relationship by linking the sex of the individuals with their hypsometric position assuming that microhabitats with higher water availability will be those that are located in lower altitudes (meters a.s.1.). Using ESRI ArcMap 9.3, a detailed hypsometric map of the studied area with precision of $1 \mathrm{~m}$ a.s.l. was done and position of 654 individuals was specified. The relationship between location a.s.l. and sex was explored with contingency table (chi-square $\left[\chi^{2}\right]$ test, JMP software; SAS Institute).

\section{Results}

\section{Genetic diversity}

Genetic diversity estimators are presented in Table 1 in Supplementary materials. There were no significant differences between sexes in the average number of alleles per locus ( $A=4.94$ in females and $A=5.25$ in males, $p=0.743$ ), average observed heterozygosity $\left(H_{O}=0.602\right.$ in females and $H_{o}=0.573$ in males, $p=0.822$ ) or average expected heterozygosity $\left(H_{e}=0.610\right.$ in females and $H_{e}=0.592$ in males, $p=0.812)$. Null alleles were inferred at some loci in both sexes at similar and rather low level (on average 0.038 and 0.039 in females and genets, respectively). A significant excess of homozygotes $(p<0.001)$ was detected in both sexes ( $F_{I S}=0.045$ in females and $F_{I S}=0.032$ in male genets), which may suggest inbreeding - matings among relatives in this case (see results of pedigree analysis).

\section{Clonality and clonal architecture}

Due to problems with the determination of sex in some individuals, 654 out of 672 trees were finally included in the genetic analysis. Among these trees, 66 different genets were defined. Twenty-eight genotypes were singletons; they produced no ramets (18 male and 10 female). The remaining genets were clustered into 38 genets -23 male and 15 female with a total of 458 and 168 ramets, respectively. All ramets within a male clone were associated with a $p$ sex $<10^{-11}$ and within female clones with a psex $<10^{-9}$. A significant malebiased sex ratio occurred at the ramet level $(1: 2.67, p<0.001)$ and at the genet level $(1: 1.64, p=0.049)$.

The male clonal diversity index was lower $(R=0.09)$ than that of females $(R=0.13)$. Male and female clones showed a low level of intermingling and the mean dominance indexes were high and comparable: $D c=0.86$ and $D c=0.82$ $(p=0.388)$, respectively. Female and male clones significantly $(p=0.0013)$ differed with respect to the average area shared with other clone(s), and it was $25.10 \%$ of their own clone area in females and $19.11 \%$ in males. The intra-clonal distance to the nearest neighbor, $d_{\text {near }}$, ranged in female clones from 0.10 to $11.73 \mathrm{~m}$ (mean $4.00 \mathrm{~m} ; \mathrm{SD}=3.44 \mathrm{~m}$ ) and in male clones from 0.43 to $18.34 \mathrm{~m}$ (average $2.44 \mathrm{~m}$; $\mathrm{SD}=3.75 \mathrm{~m}$ ); sexes were not different with respect to the value of average, $d_{\text {near }}$ $(p=0.801)$. Neither in female nor male clones, the relationship between the number of ramets and the average $d_{\text {near }}$ was statistically significant $\left(r^{2}=0.245, p=0.0832\right.$ and $r^{2}=0.143$, $p=0.0835$, respectively).

Female and male genet size, defined as the number of ramets per genet, ranged from 2 to 45 (mean 11.20; $\mathrm{SD}=11.5$ ) and from 2 to 135 (mean 19.86; SD $=27.41$ ), respectively. The maximum distance between ramets ranged from 17.20 to $82.69 \mathrm{~m}$ (mean $42.84 \mathrm{~m} ; \mathrm{SD}=22.67 \mathrm{~m}$ ) in females and from 14.41 to $127.47 \mathrm{~m}$ (mean $58.86 \mathrm{~m}$; $\mathrm{SD}=36.58 \mathrm{~m}$ ) in males, and the area occupied by the genet ranged from 2.90 to $165.09 \mathrm{~m}^{2}$ in females (mean $57.18 \mathrm{~m}^{2} ; \mathrm{SD}=42.04 \mathrm{~m}^{2}$ ) and from 12.73 to $232.94 \mathrm{~m}^{2}$ in males (mean $83.82 \mathrm{~m}^{2}$; $\mathrm{SD}=57.99 \mathrm{~m}^{2}$ ). There were no statistically significant differences between sexes with regard to clone size as defined either by the number of ramets per genets $\left(N_{R}\right)(p=0.266)$, or the maximum distance between two ramets within a genet $\left(d_{\max }\right)$ ( $p=0.886)$, or by the area occupied by the genet $\left(G_{A}\right)$ $(p=0.156)$. A significant positive relationship was discovered between the number of ramets $\left(N_{R}\right)$ and the area taken by the genet $\left(G_{A}\right)$ in males $\left(r^{2}=0.444, p=0.001\right)$ while this relationship was not significant in females $\left(r^{2}=0.085, p=0.289\right)$. For both female and male genets, regression analysis indicated also a significant positive relationship between the number of ramets and $d_{\max }\left(r^{2}=0.553, p=0.004\right.$ and $r^{2}=0.341$, $p=0.003$, respectively).

\section{Spatial genetic structure and population substructure}

At the female and male ramet level, the regression of $F_{i j}$ over the natural logarithm of the geographic distance produced a significantly $(p<0.001)$ negative slope, $b=-0.0884$ and 
$b=-0.0760$, respectively (Table 2). A significant average $F_{i j}$ was noted up to $150 \mathrm{~m}$ in female and up to $250 \mathrm{~m}$ in male ramets (Figs. 2 and 3). At the genet level, the kinship-distance regression slopes were also significant $(p<0.001)$ with the value $b=-0.0239$ in females and $b=-0.0575$ in males (Table 1). The average significant values of $F_{i j}$ in female genets was found in the first distance class (up to $55 \mathrm{~m}$ ) and further in the third $(250 \mathrm{~m})$ and fourth classes $(360 \mathrm{~m})$ (Fig. 2), while that in males was found in the first three distance classes (up to $250 \mathrm{~m}$ ) (Fig. 3). Test $Z$ indicated a statistically significant difference between sexes in the values of the regression slopes at the genet $(p<0.05)$ but not at the ramet level. $S p$ statistics was almost 3-fold higher at the genet level in males than in females. Clonality significantly contributed to the intensity of SGS in females, with the regression slope $b$ of ca. 3.7-fold higher at the ramet than at the genet level $(p<0.05)$. On the contrary, the difference between male genets and male ramets in $S p$ level was not significant.

The Bayesian analysis revealed the existence of substructuring among females and males (Fig. 4). For females, the value of $\Delta K$ was highest for $K=3$, and for males for $K=2$ (Supplementary materials Fig. 1). Bar plots showed rather limited admixture for both sexes (Supplementary materials Figs. 2 and 3).

\section{Relatedness}

For $33.3 \%$ of genets, full-sibling relationships were inferred, while for $72.7 \%$ of genets, at least one half sibling was found. Additionally, we found possible maternal-offspring and paternal-offspring pairs among individuals present in the population: for eight individuals a potential father could be defined $(12.1 \%)$ and for another four individuals a potential mother tree could be defined $(6.1 \%)$ within the population.

\section{Spatial correlations between males and females}

\section{Univariate analysis}

Double-cluster model described the pattern of males very well (Table 2, Fig. 5). Empirical pair correlation function lies within the critical regions representing double-cluster process with estimated parameters. The double-cluster process for males captured two nested scales of clustering. Males were distributed in four large clusters with radii of $81.4 \mathrm{~m}\left(2 \sigma_{1}\right)$ and 63 small clusters with radii $7.18 \mathrm{~m}\left(2 \sigma_{2}\right)$. Large clusters consisted of 119 individuals, on average, and 63 small clusters nested in the large clusters. Small cluster consisted of seven males, on average. Thus, 15 small clusters represented single large cluster. Double-cluster process described the pattern of females very well, too (Table 2, Fig. 6). Females were distributed in eight large clusters with radii of $61.68 \mathrm{~m}\left(2 \sigma_{1}\right)$ and 28 small clusters with radii $5.58 \mathrm{~m}\left(2 \sigma_{2}\right)$. The average number of individuals per large and small clusters was estimated as 59 and 6 , respectively. Each large female cluster contained nine small clusters, on average.

\section{Bivariate analysis}

Males and females showed a clear tendency for spatial segregation. The $g_{12}(r)$ function was significantly below the expectation for random labeling hypothesis (Fig. 7). The distance at which the segregation took place was ca. $105 \mathrm{~m}$. Over this distance, the empirical $g_{12}(r)$ function is above the expectation indicating the mutual attraction of males and females at larger scales.

The studied area showed hypsometric variability. The bank of the Vistula river was located at the level of $26 \mathrm{~m}$ a.s.l. similarly to the bottoms of the marshes distributed within the study site which currently constitute the oxbow lakes. The upper edge of the profiles of the river, marshes, and channels present in the study site run at a height of $30 \mathrm{~m}$ a.s.l. that can be considered as the border separating current and former riverbed from the areas of higher altitude having the character of relatively flat peaks, formed at the height of 30-32 m a.s.l. The occurrence of the white poplar ramets was referred to this border altitude. The ramets within the study site were distributed as follows: $27-30 \mathrm{~m}$ a.s.1. -201 ramets $(30.73 \%)$ and 31-32 m a.s.1. -453 ramets $(69.27 \%)$. Females occurred mostly at lower elevated sites $(53.9 \%)$ while males prevailed at higher elevated sites $(77.94 \%)(p<0.001)$.

\section{Discussion}

\section{Spatial genetic structure}

Longevity of tree species such as white poplar is the basic obstacle stymieing direct exploration of the demographic processes as it requires long-term studies that exceed the timescale of the investigations presented here. Therefore, direct testing of the relationships among clonality, demography, and SGS was impossible to be done in the frame of this study, especially in the context of sex-dependent changes which would require knowledge on the sex of the offspring at the earliest stages of recruitment. However, some of our results suggest the impact of demographic processes, especially sexdifferential mortality, on sex-specific patterns of SGS.

According to our results, sexes differed significantly at the genet level with respect to the intensity of SGS as indicated by the regression slope $(b)$, which was nearly 2.5 -fold higher for males. In our opinion, sex-dependent mortality and recruitment patterns prevailing in this population may be involved in generating the sex-dependent pattern of SGS. Male-biased sex ratio noted in this population at ramet and genet level suggests lower final female input into this population, either as the result of lower recruitment success of females (generative and 
Fig. 2 Spatial genetic structure correlograms for females at genet level (a) and ramet level (b) showing mean kinship coefficient $\left(F_{i j}\right)$ between pairs of ramets or genets over ten distance classes
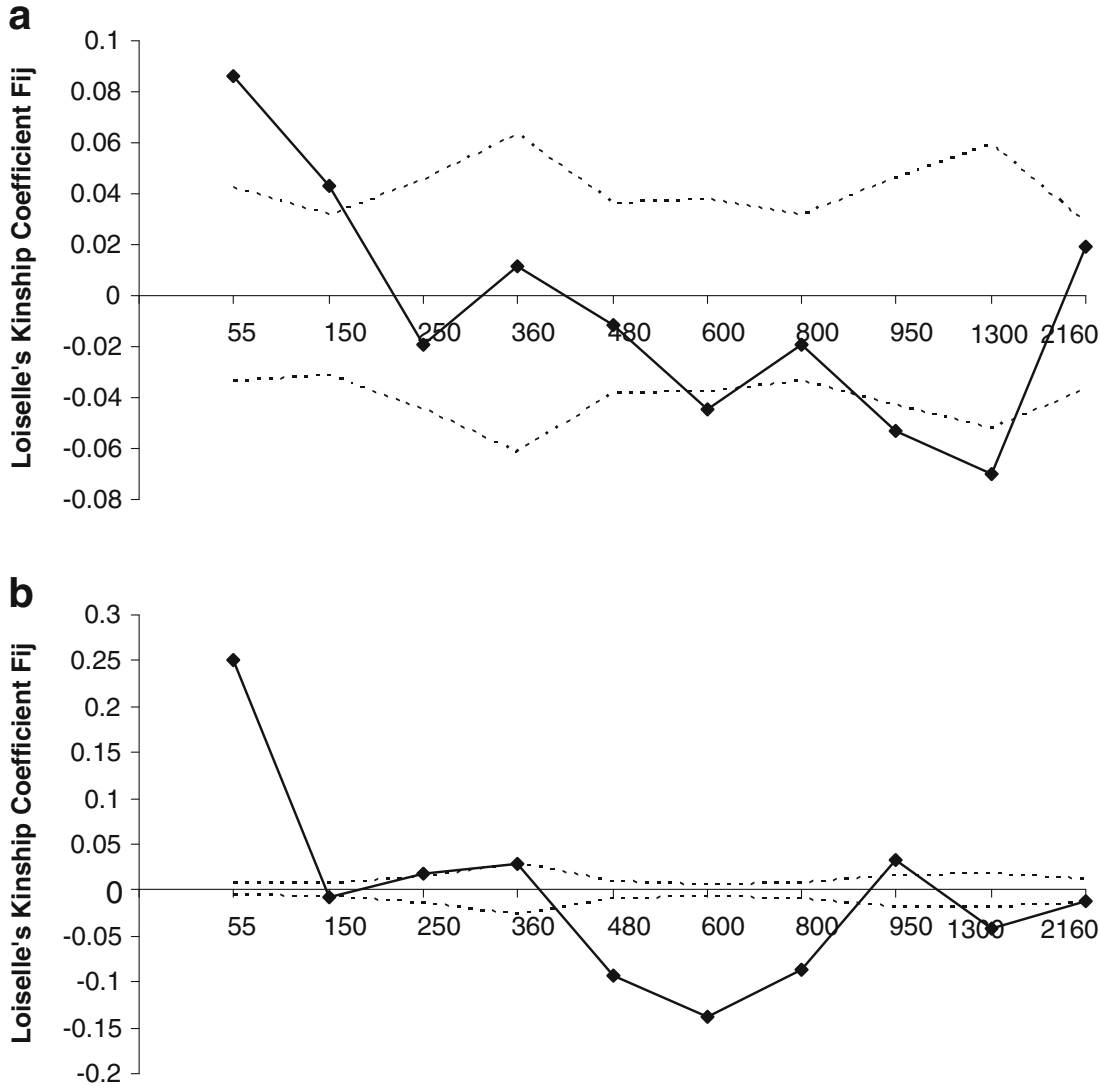

Distance (m) vegetative) and/or their higher mortality. Both processes may potentially result in fewer related female genets to be near neighbors, decreasing in this way the level of SGS. Especially, higher female mortality, which is frequently reported in dioecious species and is ascribed to their higher costs of reproduction (Obeso 2002), could be involved. Due to reproductive-related resource expenditure, females are more frequently noted in nutrient-rich microhabitats which are better for their growth and reproduction (Iszkuło et al. 2011). According to our results, the occurrence of the females of white poplar was significantly related with the local depressions (areas $<30 \mathrm{~m}$ a.s.1.). Those microhabitats may be occupied by females due to resource availability, in this case water. Some studies indicated that poplar female trees exhibit less tolerance for drought stress than male trees (Xu et al. 2008; Chen et al. 2010), which may explain the observations that on local elevations (>30 $\mathrm{m}$ a.s.1.) males were mostly noted. However, during the spring thawing and flooding events, those local depressions are the locations of water standing over (personal observation) that may be the source of the waterlogging stress contributing to female mortality. In an experiment of waterlogging conditions, female clones of Populus deltoides were shown to be more affected by water stress than males that generally showed better eco-physiological response for this kind of stress (Yang et al. 2011). Accordingly, we postulate that higher mortality of females may be the possible factor of their lower SGS in comparison to males, although long-term studies on population dynamics would be necessary to fully verify this hypothesis.

Another important factor of sex-specific SGS might be the sex-specific competitive interactions. Intra-genet and intergenet competitive interactions are very important elements of the dynamics of clonal plant populations (Watkinson and Powell 1993; Herben and Hara 1997). Significantly greater average area shared with other genets in case of females may suggest lower competitive response of females (Goldberg 1996) that may also negatively affect their recruitment and/or increase mortality.

Indirectly, analysis of SGS also suggests a high level of relatedness in this population. The degree of co-ancestry at 0.25 indicates full-sibs and 0.125 half-sibs (Loiselle et al. 1995), and the value of the average kinship coefficient in the first distance class for males in our study was 0.198. It suggests considerable relatedness among males. In contrast, for female genets, the respective coefficient was 0.086. As mentioned above, higher mortality of females could be one of the factors lowering overall relatedness among them that would result in lower SGS. Analysis of relatedness conducted with Colony supported the existence of profound sibship structure which could be the component of the SGS noted in females 
Fig. 3 Spatial genetic structure correlograms for males at genet level (a) and ramet level (b) showing mean kinship coefficient $\left(F_{i j}\right)$ between pairs of ramets or genets over ten distance classes
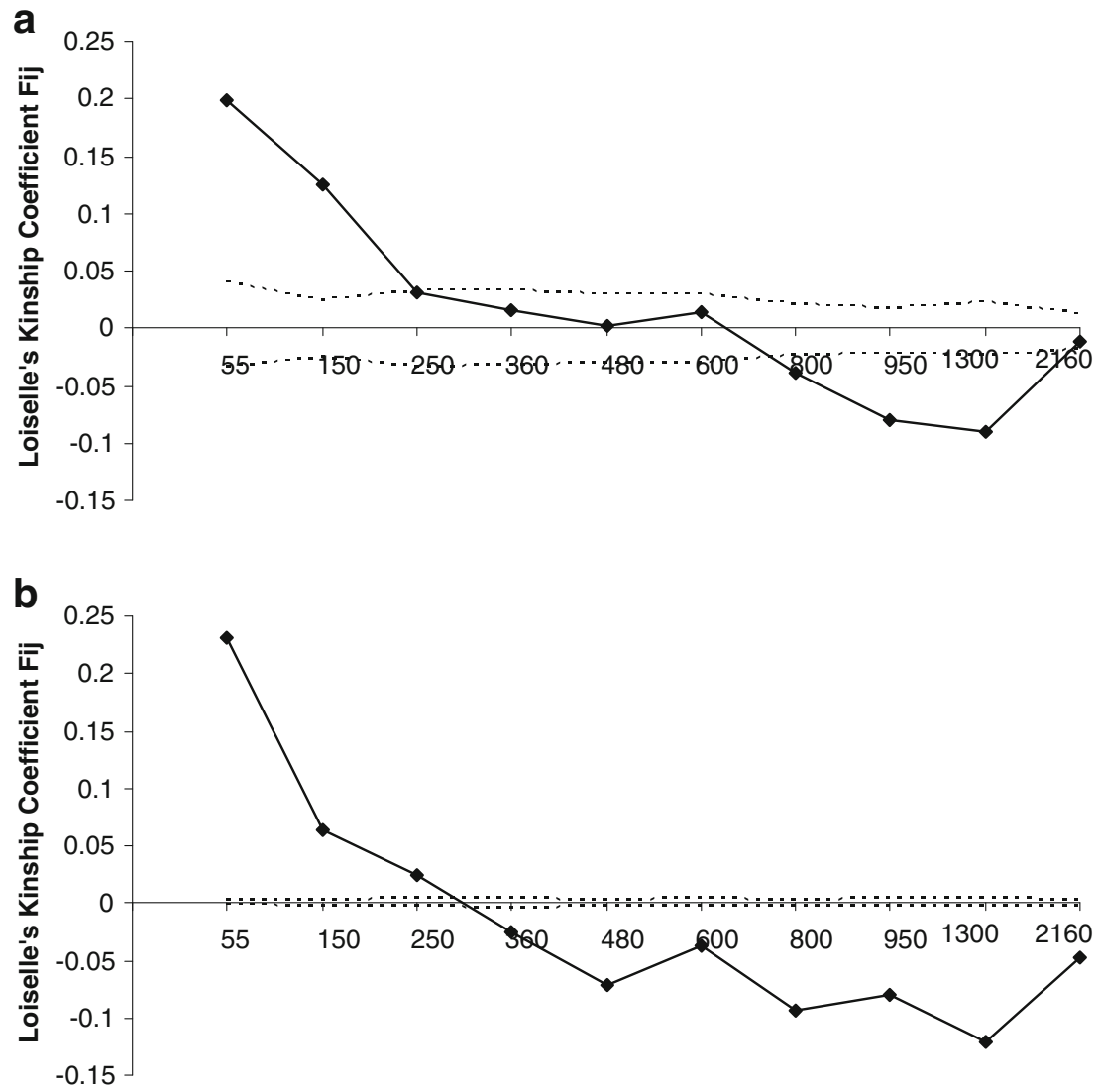

Distance (m)

and males. For over $30 \%$ of individuals from the studied population, full-sibling relationships were inferred, which strongly suggests the predomination of within-population crossings and recruitment events. Based on parentage analysis, Pospíśková and Šálková (2006) indicated domination of within-population pollinations in studied black poplar stands $-77 \%$ of offspring were fathered by males from the local population.

Divergent patterns of SGS between sexes are manifested also by the variable impact of clonality. In females, clonality

Table 1 Spatial genetic structure parameters for female and male individuals of white poplar from the study site

\begin{tabular}{llll}
\hline & $F_{i j(55 m)}$ & $b_{\log }$ & $S p$ \\
\hline Females & & & \\
$\quad$ Ramets & $0.251(0.0288)$ & $-0.0884(0.0122)$ & 0.118 \\
Genets & $0.086(0.0124)$ & $-0.0239(0.0033)$ & 0.026 \\
Males & & & \\
$\quad$ Ramets & $0.230(0.0312)$ & $-0.0760(0.0065)$ & 0.098 \\
Genets & $0.198(0.0272)$ & $-0.0575(0.0089)$ & 0.072 \\
\hline
\end{tabular}

$F_{i j(55 m)}$ average kinship coefficient between individuals from the first distance class, $b_{l o g}$ the regression slope of $F_{i j}$ on log spatial distance given with $\mathrm{SD}, S p$ index of spatial genetic structure intensity largely contributed to SGS noted at the ramet level, whereas it was not a significant factor of SGS among male ramets, either in its strength or spatial extent. This result probably reflects a difference in the overall level of relatedness among genets of a particular sex, which is higher for males. Due to such high relatedness among male genets, the contribution of clonality to SGS seemed to be negligible, and sibship structure appeared as the main driving factor of strong SGS at both the ramet and genet levels in males.

We suppose that two processes may be responsible for strong sibship structure and SGS occurring in females and males in studied population: (1) low gene dispersal by both seeds and pollen and (2) predomination of within-population matings resulting in within-population recruitment events. Generally, wind-dispersed and wind-pollinated tree species, such as poplars, are expected to present a close-to-random spatial arrangement of individuals (Vekemans and Hardy 2004) as this gene dispersal mechanism is thought to prevent kin structure. There are no studies on gene flow distance in white poplar, but a study in congeneric black poplar suggests a rather shortdistance gene flow (Rathmacher et al. 2010). On the other hand, Imbert and Lefèvre (2003) reported that gene flow in black poplar rely in majority on pollen movement but is largely inefficient due to the lack of sites suitable for requirement. The occurrence of white poplar is highly fragmented in Poland and 

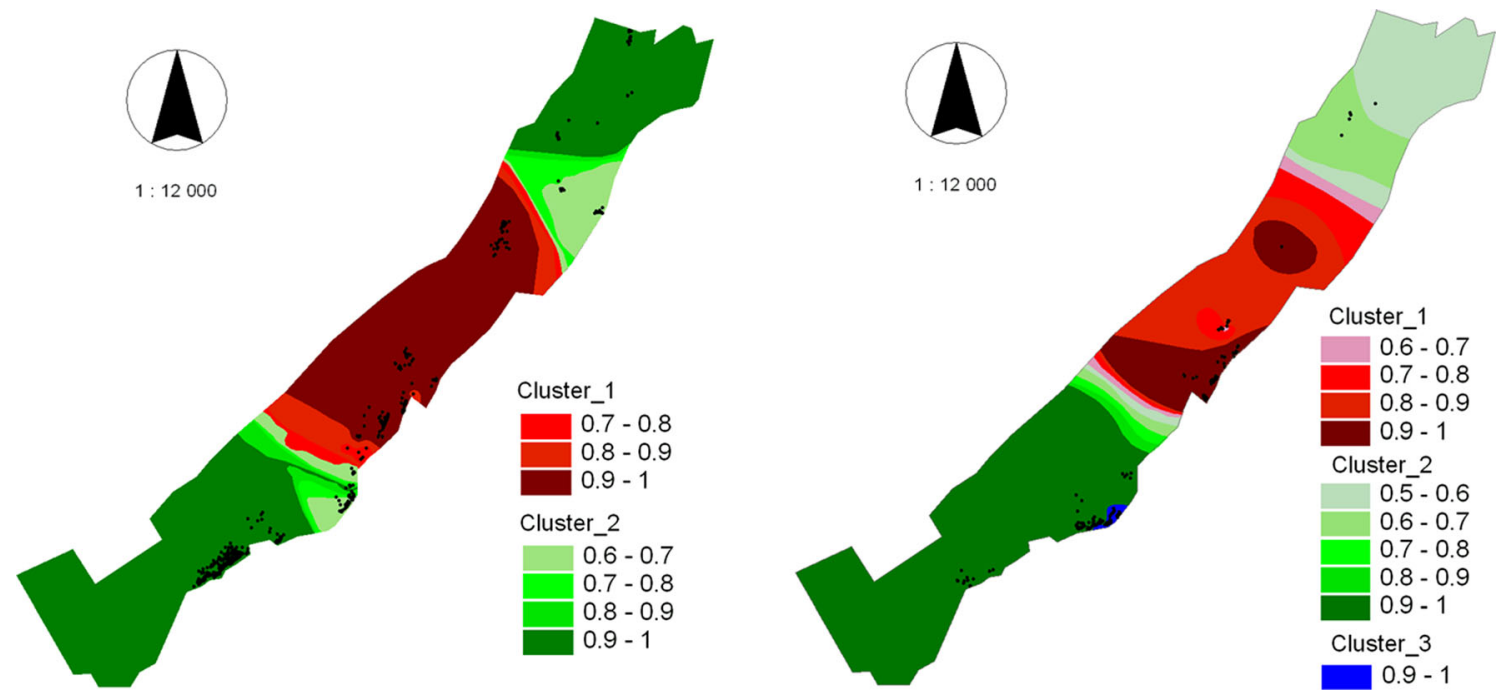

Fig. 4 Interpolated map for the ancestry coefficients obtained for male (left) and female (right) individuals of white poplar in results of population structure analysis conducted with Structure

in Europe in general, and alterations of riverine ecosystems transformed existing habitats making them unsuitable for natural regeneration. The lack of habitats and fragmentation of those sites that are left probably reduced gene flow, creating conditions for SGS to arise. White poplar, which regeneration strategy is intimately connected with flood disturbance which forms fresh, open, and bare new alluvial deposits, rarely regenerates within the study site due to lack of suitable edaphic and hydrological conditions (personal observations).

Sex-specific cost of reproduction and differential resources requirements may lead to occupation of different microhabitats by each sex which directly refers to SSS (Bierzychudek and Eckhart 1988; Van Drunen and Dorken 2014). Recently, Van Drunen and Dorken (2014) reported that SSS may be common among clonal species. According to the authors, the positive association between clonality and SSS may be "false positive" and stem due to non-random distribution of male and female ramets within the genet due to clonal growth. However, our analysis suggests that a significant relationship between sex of the individuals and their hypsometrical location may exist. This would mean that observed SSS could be induced with difference in microhabitat quality and not with clonality itself. In our opinion, SSS could be involved in generating sexspecific SGS because different microhabitats might be the source of different spatial patterns producing a differential course of demographic processes (Barot et al. 1999) that stays in close relationship with population genetic structure.

\section{Sex-specific clonal architecture and growth}

Based on dominance index, we inferred that the ramets of both sexes presented a rather clumped occurrence within a genet, a pattern defined as the phalanx strategy of growth, commonly found in many woody species (Peterson and Jones 1997) including species from Populus (Namroud et al. 2005; Chenault et al. 2011; Cristobal et al. 2014). Spatial analysis also detected the non-random distribution of individuals (ramets) of both sexes in space (Table 2). This kind of clonal architecture is frequently reported in populations with significant SGS, which suggests that it may be one of the important factors supporting SGS (Vandepitte et al. 2009; Mizuki et al. 2010; Dodd et al. 2013).

Generally, differences between sexes in parameters describing clonal growth such as gene size and number of ramets per genet were not significant. Existing data on this issue in other species are scarce and not conclusive as they show within-species variability. The larger size of male genets compared to those of females in terms of ramet number and genet spatial extension was reported for Populus tremuloides Michx. (Comtois et al. 1986) and Populus euphratica Oliv.
Table 2 Fitted parameters of the double-cluster process for Populus data set

\begin{tabular}{|c|c|c|c|c|c|c|c|c|}
\hline & \multicolumn{4}{|c|}{ Large clusters } & \multicolumn{4}{|c|}{ Small clusters } \\
\hline & $2 \sigma_{1}$ & $100 \rho_{1}$ & $\mu_{1}=\lambda_{1} / N_{\text {cluster } 1}$ & $N_{\text {cluster1 }}$ & $2 \sigma_{2}$ & $100 \rho_{2}$ & $\mu_{2}=\lambda_{2} / N_{\text {cluster } 2}$ & $N_{\text {cluster2 }}$ \\
\hline Males & 81.40 & 0.00016 & $\approx 119$ & 4 & 7.18 & 0.00045 & $\approx 7$ & 63 \\
\hline Females & 61.68 & 0.00013 & $\approx 59$ & 8 & 5.58 & 0.00012 & $\approx 6$ & 28 \\
\hline
\end{tabular}

$\mu 1, \mu 2$ mean number of individuals in large and small clusters, respectively; $N_{\text {cluster } 1}, N_{\text {cluster } 2}$ number of large and small clusters, respectively 
Fig. 5 Pair correlation function calculated for males only with double-cluster null model. Solid thick line - empirical function; dashed lines-fifth-highest and fifth-lowest values of pair correlation function of 199 Monte Carlo simulations of the fitted double-cluster process and expectation (solid thin line)

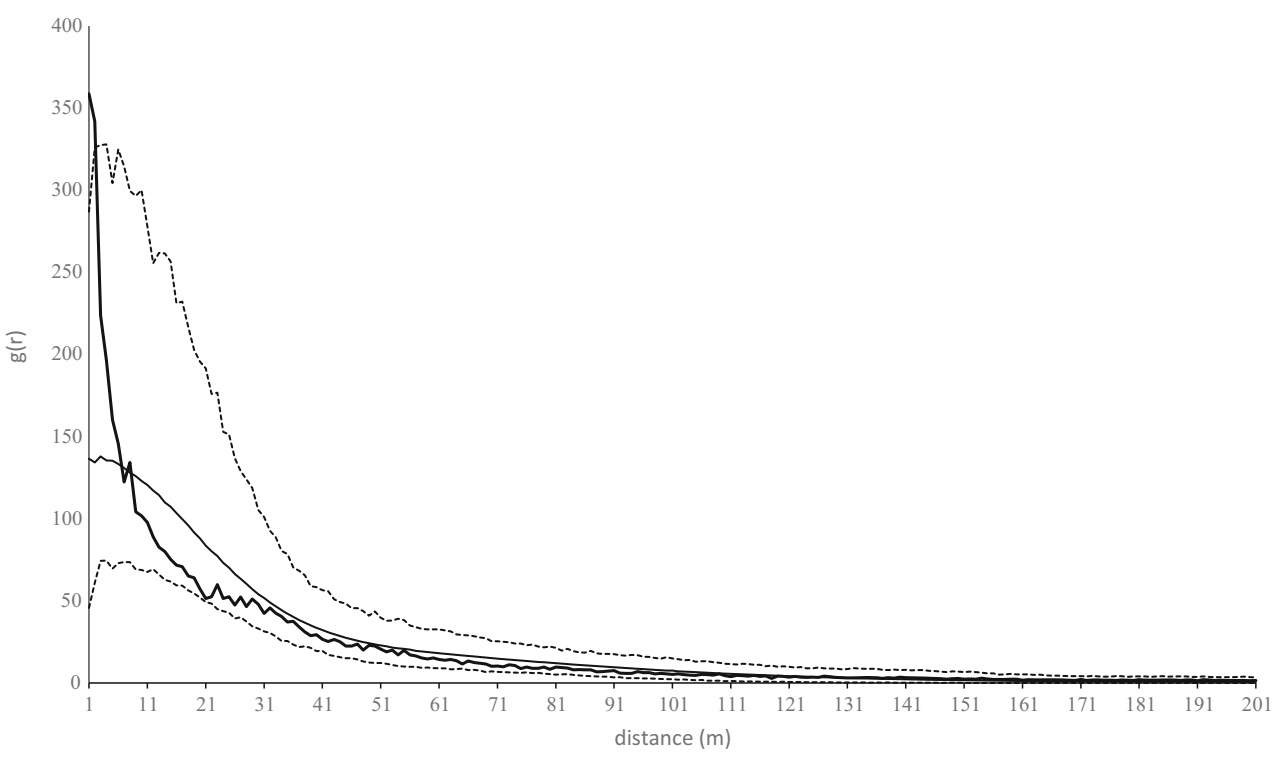

(Petzold et al. 2013). In Populus nigra L., Sakai and Burris (1985) reported a greater number of ramets in females, while Chenault et al. (2011) reported similar genet sizes in males and females. Matsushita and Tomaru (2012) suggested a lack of significant sex-dependent differences in clone sizes measured with the number of ramets in the shrub Lindera trilobata Thunb. Perhaps, that there is no simple relationship between ramet production and sex and other genetic or/and ecological conditions may be involved. The difference between sexes in clumping pattern was noticeable only at the ramet level and concerned the scale of the process which was greater for males (Table 2).

The significant positive relationship of the number of ramets $\left(N_{R}\right)$ with the area occupied by the clone and maximal distance between ramets $\left(d_{\max }\right)$ and lack of significant relationship between $N_{R}$ and $d_{\text {near }}$ (nearest neighbor distance) may suggest that the process of clonal growth is a process of expansion for male clones. For female clones, only the relationship between the number of ramets and $d_{\max }$ was positively significant. This may suggest a different strategy of clonal growth in females and males at this site. We interpret the positive relationship between $N_{R}$ and $d_{\max }$ without expanding the area occupied by females as directionality in their clonal growth. Females in their clonal spread might be more oriented towards foraging of resources or/and avoiding competition. From that reason, they would place new ramets in a new space and do not densify an occupied area (for female clones, the relationship between $N_{R}$ and $d_{\text {near }}$ was insignificant).

In our study, a significant deviation from an expected 1:1 ratio towards males was noted at the ramet level $(1: 2.67, p<0.001)$ and at the genet level $(1: 1.64, p=0.049)$ as well. Ramet-level male-biased sex ratio is frequently reported among clonal species and is ascribed to more intensive clonal reproduction of males (Allen and Antos 1993; Matsushita and Tomaru 2012; Petzold et al. 2013; Yakimowski and Barrett 2014). Male-biased sex ratios either at the ramet or genet level are commonly attributed also to higher mortality in females, which is linked to their higher
Fig. 6 Pair correlation function calculated for females only with double-cluster null model. Solid thick line-empirical function; dashed lines - fifth-highest and fifth-lowest values of pair correlation function of 199 Monte Carlo simulations of the fitted double-cluster process and expectation (solid thin line)

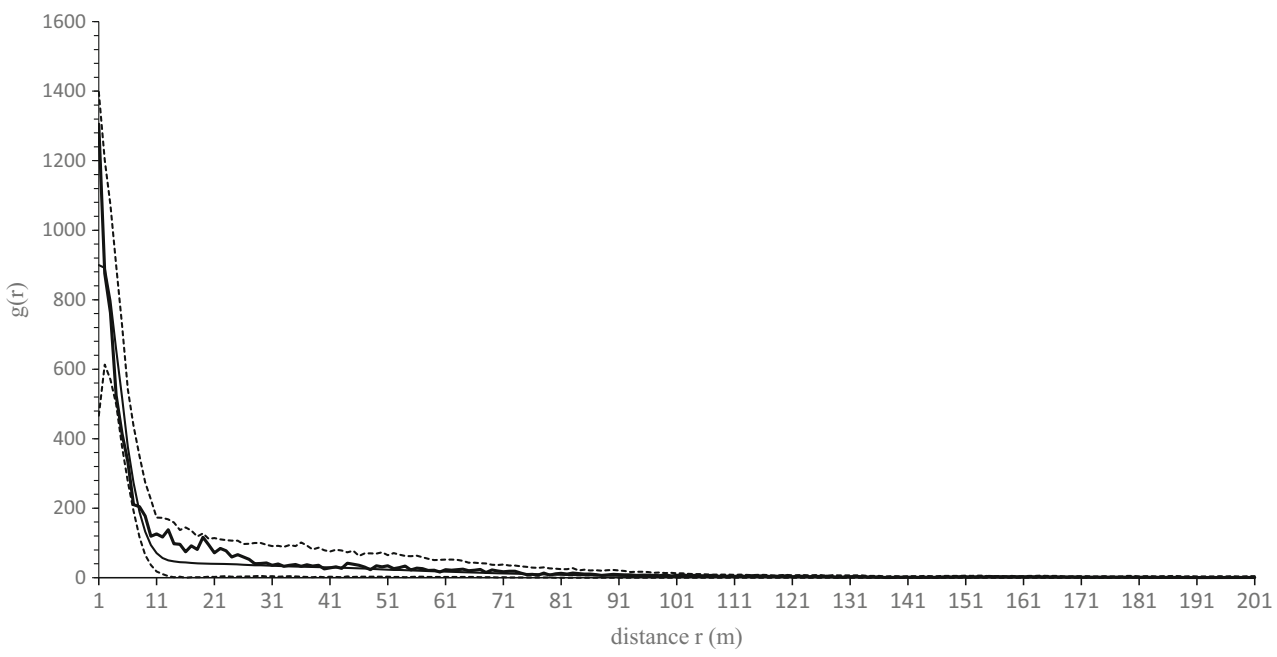


Fig. 7 Bivariate analysis of the spatial correlation between males (type 1) and females (type 2) of Populus ramets, based on the pair correlation function. Solid thick line - empirical $g_{12}(r)$; dashed lines - fifth-highest and fifthlowest values of pair correlation function of 199 Monte Carlo simulations of the random labeling null model

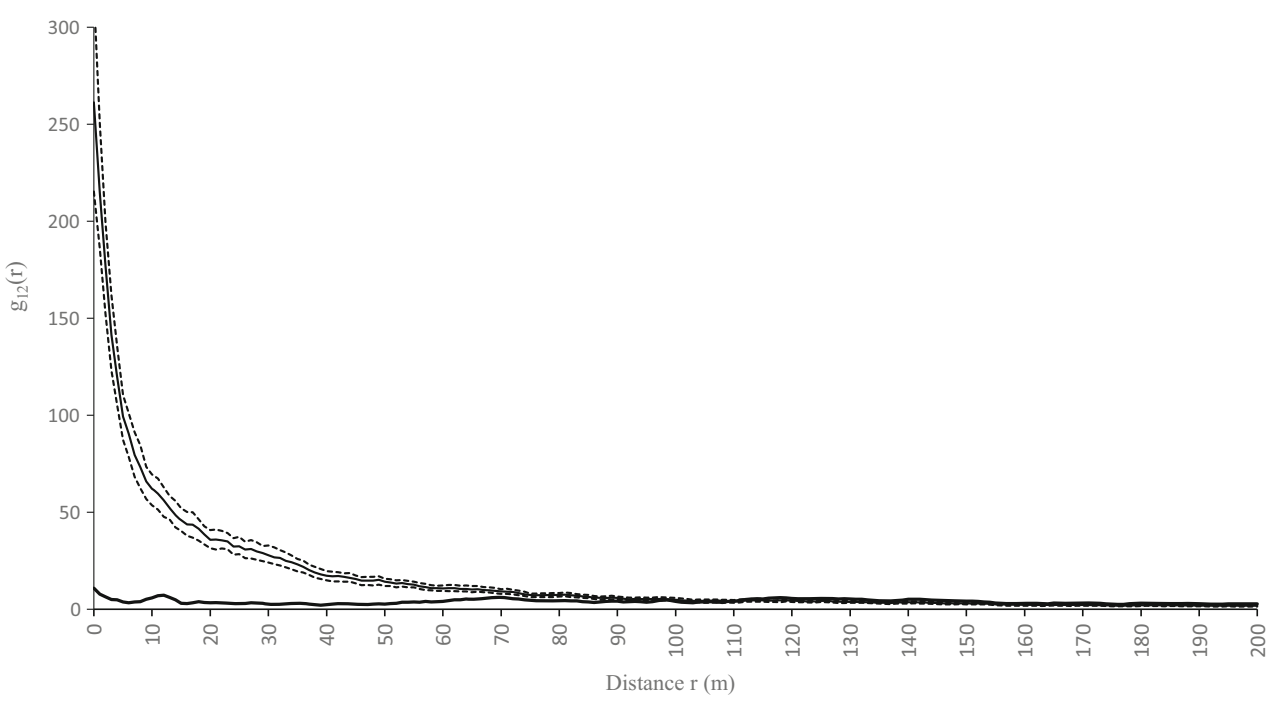

resource demands (Lloyd and Webb 1977; Obeso 2002) leading to resource allocation trade-offs affecting survival rates (Allen and Antos 1993; Petzold et al. 2013). None of these was monitored by us in field as the single-season study design precludes tracing the dynamics of the ramet production or mortality which requires long-term observation, especially in long-living tree species. And so, we cannot conclude on primary factors of malebiased ratio. However, higher female mortality serves as a feasible explanation.

\section{Conclusions}

In general, we feel that high SGS and relatedness noted in females and males in studied population represents a rather abnormal course of population processes. Considering overall reproductive biology of the species (wind pollination, wind and water dispersion of seeds produced in high amounts, high germination rate, etc.), limitations in gene dispersal should lie in external factors such as fragmentation of the species occurrence and lack of sites for recruitment. Dioecy and especially biased sex ratio that both affect the effective population density may also be responsible for SGS in the studied population.

We found clear sex-dependent patterns of SGS in a population of white poplar. Sexes differed significantly in terms of the intensity, spatial extent of SGS, and the factors that governed SGS. In males, with almost a 3-fold higher $S p$ at the genet level than females, SGS was mainly driven by an overall high relatedness. Clonality was not a significant factor, as the SGS at the genet and ramet levels were comparable. In contrast, in females, clonality was the major factor of SGS estimated at the ramet level, as $S p$ at the ramet level was 4.5fold higher than at the genet level. We suspect that the intensity of SGS at the genet level in females was driven mainly by the demographic cost of reproduction (i.e., higher mortality of females due to higher reproductive expenditure) resulting in their weaker SGS, although direct studies are needed to fully support our hypothesis. Females and males were similar with respect to clone sizes, but sexes showed different strategies of clonal growth - females showed a "foraging behavior" and/or escape strategy, while male genets were expanding their areas.

\section{Data archiving statement}

Genotypes of the individuals analyzed are available from the corresponding author after request.

Open Access This article is distributed under the terms of the Creative Commons Attribution 4.0 International License (http:// creativecommons.org/licenses/by/4.0/), which permits unrestricted use, distribution, and reproduction in any medium, provided you give appropriate credit to the original author(s) and the source, provide a link to the Creative Commons license, and indicate if changes were made.

\section{References}

Allen GA, Antos JA (1993) Sex ratio variation in the dioecious shrub Oemleria cerasiformis. Am Nat 141:537-553

Arnaud-Haond S, Belkhir K (2006) Genclone: a computer program to analyse genotypic data, test for clonality and describe spatial clonal organization. Mol Ecol Notes 7:15-17

Barot S, Gignoux J, Menaut J-C (1999). Demography of a Savanna Palm Tree: Predictions from Comprehensive Spatial Pattern Analyses. Ecology 80:1987-2005

Bell G (1980) The costs of reproduction and their consequences. Am Nat 116:45-76

Bierzychudek P, Eckhart V (1988) Spatial segregation of the sexes of dioecious plants. Am Nat 132:34-43 
Chen L, Zhang S, Zhao H, Korpelainen H, Li C (2010) Sex-related adaptive responses to interaction of drought and salinity in Populus yunnanensis: sexually differing responses to drought and salt in poplar. Plant Cell Environ 33:1767-1778

Chenault N, Arnaud-Haond S, Juteau M, Valade R, Almeida J-L, Villar M, Bastien C, Dowkiw A (2011) SSR-based analysis of clonality, spatial genetic structure and introgression from the Lombardy poplar into a natural population of Populus nigra L. Along the Loire River. TGG 7:1249-1262

Chong C, Edwards W, Pearson R, Waycott M (2013) Sprouting and genetic structure vary with flood disturbance in the tropical riverine paperbark tree, Melaleuca leucadendra (Myrtaceae). Am J Bot 100:2250-2260

Chybicki IJ, Burczyk J (2009) Simultaneous estimation of null alleles and inbreeding coefficients. J Hered 100:106-113

Chybicki IJ, Burczyk J (2013) Seeing the forest through the trees: comprehensive inference on individual mating patterns in a mixed stand of Quercus robur and Q. petraea. Ann Bot 112:561-574

Comtois P, Simon JP, Payette S (1986) Clonal constitution and sex ratio in northern populations of balsam poplar Populus balsamifera. Ecography 9:251-260

Cristobal D, Martinez-Zurimendi P, Villamediana I, Ciriza J, Villar J, Nanos N, Sierra-de-Grado R (2014) Clonal structure and dynamics of peripheral Populus tremula L. populations. I-Forest 7:140-149

Delph LF (1999) Sexual dimorphism in life history. In: Geber PDMA, Dawson PDTE, Delph PDLF (eds) Gender and sexual dimorphism in flowering plants. Springer, Berlin Heidelberg, pp. 149-173

Dering M, Chybicki IJ, Rączka G (2015) Clonality as a driver of spatial genetic structure in populations of clonal tree species. Plant Res 128:731-745

Dodd RS, Mayer W, Nettel A, Afzal-Rafii Z (2013) Clonal growth and finescale genetic structure in tanoak (Notholithocarpus densiflorus: Fagaceae). J Hered 104:105-114

Dorken ME, Barrett SCH (2004) Phenotypic plasticity of vegetative and reproductive traits in monoecious and dioecious populations of Sagittaria latifolia (Alismataceae): a clonal aquatic plant. J Ecol 92:32-44

Dorken ME, Eckert CG (2001) Severely reduced sexual reproduction in northern populations of a clonal plant, Decodon verticillatus (Lythraceae). J Ecol 89:339-350

Dumolin S, Demesure B, Petit RJ (1995) Inheritance of chloroplast and mitochondrial genomes in pedunculate oak investigated with an efficient PCR method. TAG 91:1253-1256

Evanno G, Regnaut S, Goudet J (2005) Detecting the number of clusters of individuals using the software structure: a simulation study. Mole Ecol 14:2611-2620

Fujitaka T, Sakai S (2007) Sexual dimorphism in clonal growth forms and ramet distribution patterns in Rumex acetosella (Polygonaceae). Ecol Res 22:248-254

Geraldes A, Hefer CA, Capron A, Kolosova N, Martinez-Nuñez F, Soolanayakanahally RY, Staton B, Guy RD, Mansfield SD, Douglas CJ, Cronk QCB (2015) Recent Y chromosome divergence despite ancient origin of dioecy in poplars (Populus). Mol Ecol 24:3243-3256

Goldberg DE (1996) Competitive Ability: Definitions, Contingency and Correlated Traits. Philos TRoy Soc B 351:1377-1385

Hardy OJ, Vekemans X (2002) Spagedi: a versatile computer program to analyse spatial genetic structure at the individual or population levels. Mol Ecol Notes 2:618-620

Heilbuth JC, Ilves KL, Otto SP (2001) The consequences of dioecy for seed dispersal: modeling the seed-shadow handicap. Evolution 55:880-888

Herben T, Hara T (1997) Competition and spatial dynamics of clonal plants. In: de Kroon H, van Groenendael J (eds) The ecology and evolution of clonal plants. Backhuys Publishers, 331-357.

Heuertz M, Vekemans X, Hausman J-F, Palada M, Hardy OJ (2003) Estimating seed vs. pollen dispersal from spatial genetic structure in the common ash. Mol Ecol 12:2483-2495

Illian J, Penttinen A, Stoyan H, Stoyan D (2008) Statistical analysis and modelling of spatial point patterns. John Wiley and Sons, Chichester
Imbert E, Lefèvre F (2003) Dispersal and gene flow of Populus nigra (Salicaceae) along a dynamic river system. J Ecol 91:447-456

Isogimi T, Matsushita M, Watanabe Y, Nakagawa M (2011) Sexual differences in physiological integration in the dioecious shrub Lindera triloba: a field experiment using girdling manipulation. Ann Bot 107:1029-1037

Iszkuło G, Boratyński A (2011) Initial period of sexual maturity determines the greater growth rate of male over female in the dioecious tree Juniperus communis subsp. communis. Acta Oecol 37:99-102

Iszkuło G, Jasinska AK, Sobierajska K (2011) Dendroecological differences between Taxus baccata males and females in comparison with monoecious Abies alba. Dendrobiology 65:55-61

Jacquemyn H, Endels P, Honnay O, Wiegand T (2010) Evaluating management interventions in small populations of a perennial herb Primula vulgaris using spatio-temporal analyses of point patterns. J Appl Ecol 47:431-440. doi:10.1111/j.1365-2664.2010.01778.x

Jeník J (1994) Clonal growth in woody plants: A review. Folia Geobot 29:291-306

Kopelman N, Mayzel J, Jakobsson M, Rosenberg N, Mayrose I (2015) Clumpak: a program for identifying clustering modes and packaging population structure inferences across K. Mole Ecol Res 15:11791191

Lloyd DG, Webb CJ (1977) Secondary sex characters in plants. Bot Rev 43:177-216

Loiselle BA, Sork VL, Nason J, Graham C (1995) Spatial genetic structure of a tropical understory shrub, Psychotria officinalis (Rubiaceae). Am J Bot 82:1420-1425

Matsuo A, Tomimatsu H, Suzuki J-I, Saitoh T, Shibata S, Makita A, Suyama Y (2014) Female and male fitness consequences of clonal growth in a dwarf bamboo population with a high degree of clonal intermingling. Ann Bot 114:1035-1041

Matsushita M, Tomaru N (2012) Differences in clonal integration between the sexes: long-term demographic patterns in the dioecious, multistemmed shrub Lindera triloba. Botany 90:1028-1035

McLetchie DN, Puterbaugh MN (2000) Population sex ratios, sex-specific clonal traits and tradeoffs among these traits in the liverwort Marchantia inflexa. Oikos 90:227-237

Meirmans PG (2012) The trouble with isolation by distance. Mol Ecol 21: 2839-2846

Mizuki I, Ishida K, Tani N, Tsumura Y (2010) Fine-scale spatial structure of genets and sexes in the dioecious plant Dioscorea japonica, which disperses by both bulbils and seeds. Evol Ecol 24:1399-1415

Montesinos D, Villar-Salvador P, García-Fayos P, Verdú M (2012) Genders in Juniperus thurifera have different functional responses to variations in nutrient availability. New Phytol 193:705-712

Namroud M-C, Park A, Tremblay F, Bergeron Y (2005) Clonal and spatial genetic structures of aspen (Populus tremuloides Michx.). Mol Ecol 14: 2969-2980

Nazareno AG, Alzate-Marin AL, Pereira RAS (2013) Dioecy, more than monoecy, affects plant spatial genetic structure: the case study of Ficus. Ecol Evol 3:3495-3508

Obeso JR (2002) The costs of reproduction in plants. New Phytol 155:321-348

Ohsako T (2010) Clonal and spatial genetic structure within populations of a coastal plant, Carex kobomugi (Cyperaceae). Am J Bot 97:458-470

Paolucci I, gaudet M, Jorge V, Beritognolo I, Terzoli S, Kuzminsky E, Muelo R, Mugnozza G, Sabatti M (2010) Genetic linkage maps of Populus alba L. and comparative mapping analysis of sex determination across Populus species. Tree Genet Genom 6:863-875

Peng Y, Macek P, Macková J, Romoleroux K, Hensen I (2015) Clonal diversity and fine-scale genetic structure in a high Andean Treeline population. Biotropica 47:59-65

Peterson CJ, Jones RH (1997) The ecology and evolution of clonal plants. In: de Kroons H, van Groenendael (eds) Clonality in woody plants: a review and comparison with clonal herbs. Backhuys Publishers, 263-289.

Petit RJ, Hampe A (2006) Some evolutionary consequences of being a tree. Ann Ecol Evol Sys 37:187-214 
Petzold A, Pfeiffer T, Jansen F, Eusemann P, Schnittler M (2013) Sex ratios and clonal growth in dioecious Populus euphratica Oliv., Xinjiang Prov., western China. Trees 27:729-744

Pospíšková M, Šálková I (2006) Population structure and parentage analysis of black poplar along the Morava River. Can J For Res 36:1067-1076

Pritchard JK, Stephens M, Donnelly P (2000) Inference of population structure using multilocus genotype data. Genetics 155:945-959

Rathmacher G, Niggemann M, Köhnen M, Ziegenhagen B, Bialozyt R (2010) Short-distance gene flow in Populus nigra L. accounts for small-scale spatial genetic structures: implications for in situ conservation measures. Conserv Genet 11:1327-1338

Renner SS, Ricklefs RE (1995) Dioecy and its correlates in the flowering plants. Am J Bot 82:596-606

Reusch TBH, Hukriede W, Stam WT, Olsen JL (1999) Differentiating between clonal growth and limited gene flow using spatial autocorrelation of microsatellites. Heredity 83:120-126

Rousset F (2008) genepop'007: a complete re-implementation of the genepop software for windows and Linux. Mol Ecol Resour 8:103-106

Sakai AK, Burris TA (1985) Growth in male and female aspen clones: a twenty-five-year longitudinal study. Ecology 66:1921-1927

Sánchez-Vilas J, Bermúdez R, Retuerto R (2012) Soil water content and patterns of allocation to below-and above-ground biomass in the sexes of the subdioecious plant Honckenya peploides. Ann Bot 110:839-848

van der Schoot J, Pospíšková M, Vosman B, Smulders MJM (2000) Development and characterization of microsatellite markers in black poplar (Populus nigra L.). TAG 101:317-322

Setsuko S, Ishida K, Tomaru N (2004) Size distribution and genetic structure in relation to clonal growth within a population of Magnolia tomentosa Thunb. (Magnoliaceae). Mol Ecol 13:2645-2653

Silvertown J (2008) The evolutionary maintenance of sexual reproduction: evidence from the ecological distribution of asexual reproduction in clonal plants. Int J Plant Sci 169:157-168

Tuskan GA, Gunter LE, Yang ZK, Yin T, Sewell MM, DiFazio SP (2004) Characterization of microsatellites revealed by genomic sequencing of Populus trichocarpa. Can J For Res 34:85-93

Wang X, Wiegand T, Hao Z, Li B, Ye J, Lin F (2010) Species associations in an old-growth temperate forest in North-Eastern China. J Ecol 98:674 686. doi:10.1111/j.1365-2745.2010.01644.x
Wiegand T, Martínez I, Huth A (2009) Recruitment in tropical tree species: revealing complex spatial patterns. Am Nat 174:E106-E140. doi: $10.1086 / 605368$

Wiegand T, Moloney KA (2014) Handbook of spatial point-pattern analysis in ecology. CRC Press, Taylor and Francis Gorup, Boca Raton

Vandepitte K, Honnay O, Meyer TD, Jacquemyn H, Roldán-Ruiz I (2010) Patterns of sex ratio variation and genetic diversity in the dioecious forest perennial Mercurialis perennis. Plant Ecol 206:105-114

Vandepitte K, Roldán-Ruiz I, Leus L, Jacquemyn H, Honnay O (2009) Canopy closure shapes clonal diversity and fine-scale genetic structure in the dioecious understorey perennial Mercurialis perennis. J Ecol 97:404 414

Van Drunen WE, Dorken ME (2014) Wind pollination, clonality, and the evolutionary maintenance of spatial segregation of the sexes. Evol Ecol 28:1121-1138

Van Drunen WE, van Kleunen M, Dorken ME (2015) Consequences of clonality for sexual fitness: Clonal expansion enhances fitness under spatially restricted dispersal. PNAS 112:8929-8936

Vekemans X, Hardy OJ (2004) New insights from fine-scale spatial genetic structure analyses in plant populations. Mol Ecol 13:921-935

Vessella F, Salis A, Scirè M, Piovesan G, Schirone B (2015) Natural regeneration and gender-specific spatial pattern of Taxus baccata in an oldgrowth population in Foresta umbra (Italy). Dendrobiology 73:75-90

Wang J, Santure AW (2009) Parentage and sibship inference from multilocus genotype data under polygamy. Genetics 181:1579-1594

Watkinson AR, Powell JC (1993) Seedling recruitment and the maintenance of clonal diversity in plant populations - a computer simulation of Ranunculus repens. J Ecol 81:707-717

Weir BS, Cockerham CC (1984) Estimating F-statistics for the analysis of population structure. Evolution 38:1358-1370

Yakimowski SB, Barrett SCH (2014) Clonal genetic structure and diversity in populations of an aquatic plant with combined vs. separate sexes. Mol Ecol 23:2914-2928

Yang F, Wang Y, Wang J, Deng W, Liao L, Li M (2011) Different ecophysiological responses between male and female Populus deltoides clones to waterlogging stress. For Ecol Manag 262:1963-1971

Xu X, Peng G, Wu C, Korpelainen H, Li C (2008) Drought inhibits photosynthetic capacity more in females than in males of Populus cathayana. Tree Physiol 28:1751-1759 